\title{
WAWASAN AL-QUR'AN TENTANG RADIKALISME DAN PENANGANANNYA DI ERA MILENIAL
}

\author{
Wiji Nurasih \\ Institut Agama Islam Negeri Purwokerto \\ wijin2409@gmail.com
}

\begin{abstract}
This paper seeks to examine the insights of the Qur'an about radicalism and how to deal with it in the millennial era by utilizing information technology to realize moderate Islam. At present the notion of radicalism has spread through various means and has become a troubling problem. This needs to be dealt with seriously in order to realize peace and tranquility in life throughout the world. Al-Qur'an as a way of life for Muslims also contains things about the problems of mankind, instructions for their settlement and so forth. So in this paper we will examine how the Qur'an talks about radicalism and seek solutions to these problems. Data sources were obtained through literature review and explained descriptively analytically. The study was conducted through a review of several interpretations of the Qur'an and other supporting sources. From this study, the results show that human radical behavior that occurs among humans has been described in Surat al-Baqarah verse 30. Then in this verse also Allah SWT states that he will make a caliph on earth. Departing from this verse, the author tries to contextualize it now so that the millennial generation can play a role in addressing and overcoming the phenomenon of radicalism by utilizing information technology in accordance with the guidance of the Qur'an
\end{abstract}

Keywords: Radicalism, the Qur'an and information technology

\begin{abstract}
ABSTRAK
Tulisan ini berusaha mengkaji wawasan al-Qur'an tentang radikalisme dan cara menanggulanginnya di era milenial dengan memanfaatkan teknologi informasi agar terwujud Islam yang moderat. Saat ini paham radikalisme telah menyebar melalui berbagai cara dan menjadi masalah yang meresahkan. Hal ini perlu ditangani dengan serius guna terwujudnya kedamaian dan ketentraman dalam kehidupan di seluruh dunia. Al-Qur'an sebagai way of life bagi muslim juga memuat hal-hal mengenai problematika umat manusia, petunjuk penyelesaiannya dan lain sebagainya. Sehingga dalam tulisan ini akan dikaji bagaimana al-Qur'an berbicara tentang perilaku radikalisme dan mencari solusi dari persoalan tersebut. Sumber data diperoleh melalui kajian kepustakaan dan dijelaskan secara deskriptif analitis. Penelitian dilakukan melalui telaah terhadap beberapa tafsir alQur'an dan sumber pendukung lain. Dari kajian ini diperoleh hasil bahwa
\end{abstract}


perilaku radikal manusia yang terjadi di antara manusia telah digambarkan dalam surat al-Baqarah ayat 30. Kemudian dalam ayat ini pula Allah SWT menyatakan akan menjadikan seorang khalifah di muka bumi. Berangkat dari ayat ini, penulis berusaha mengkontekstualkannya dengan masa sekarang sehingga generasi milenial dapat berperan dalam menyikapi dan menanggulangi fenomena radikalisme dengan memanfaatkan teknologi informasi sesuai dengan tuntunan al-Qur'an

Kata kunci: Radikalisme, Al-Qur'an dan Teknologi Informasi

\section{Pendahuluan}

Saat ini penganut paham radikalisme agama semakin bercokol di berbagai tempat tak terkecuali di Indonesia. Keberadaannya bukan sekali dua kali menimbulkan keresahan bagi segenap elemen masyarakat dengan aksi-aksi teror yang berturut-turut mereka lakukan. Maka, ini menjadi masalah besar bagi bangsa Indonesia yang terancam keselamatan, keamanan, kesatuan dan persatuannya jika paham radikalisme yang anti terhadap konstitusi serta menentang moderasi Islam ini dibiarkan atau tidak ditindaklanjuti dengan serius.

Aksi teror dan kekerasan yang mereka lakukan salah satunya dipengaruhi oleh pemahaman yang terlalu tekstual terhadap al-Qur'an, sehingga perbuatan yang menentang kemanusiaan mereka klaim sebagai jihad membela agama. Salah satu contoh yang menganut aliran garis keras atau kaum ekstrimis ini adalah ISIS (Islamic State of Iraq and Suriah). Tindakan terorisme yang pernah terjadi antara lain peristiwa bom Bali I di tahun 2002, bom hotel JW Marriot I, bom Kedubes Australia, bom Bali II dan lain-lain hingga yang baru-baru ini terjadi adalah pengeboman tiga gereja di Surabaya. Dalam aksi yang mereka anggap sebagai jihad fii sabiilillah, mereka menganggap bahwa orang yang berbeda paham dengan mereka halal dibunuh meskipun keluarga dan saudara sendiri. Ini memberi kesan bahwa cara yang mereka lakukan terlalu memaksakan suatu paham yang mereka kehendaki, intoleran, dan keras yang justru menyimpang dari cara berdakwah yang diajarkan Islam. Idealnya dakwah Islam dilakukan tanpa menyakiti mad'u (penerima dakwah), mengingatkan pada kebaikan dan perbuatan dosa dengan cara yang santun, dan tanpa pemaksaan apalagi hingga melakukan pembunuhan. Dalam surat alMaidah ayat 32 disebutkan bahwa membunuh satu jiwa tanpa alasan yang benar sama saja dengan membunuh seluruh umat manusia. Pada konteks 
tertentu, boleh pula seorang da'i berdakwah dengan metode debat atau adu argumen namun tetap dengan cara yang baik dan damai (Juhri).

Yang menjadi permasalahan, penyebaran paham radikal yang mendorong pada tindak terorisme saat ini semakin sulit dibendung. Motif penyebaran paham radikalisme agama ini tidak dilakukan dengan satu cara. Mereka juga aktif menggunakan kecanggihan teknologi informasi untuk menyebarkan paham yang keliru kepada masyarakat. Karena itu, semua elemen bangsa dari pemerintah hingga masyarakatnya perlu menyadari gerakan mereka dan terus mengembangkan cara penanganan atas penyebaran paham radikalisme ini mulai dari cara yang fisik hingga menanganinya melalui penguasaan dan pengawasan terhadap teknologi informasi.

Dalam tulisan ini, penulis hendak mengkaji peristiwa-peristiwa terorisme sebagai suatu pertumpahan darah menurut surat al-Baqarah ayat 30 kemudian mencari solusi yang tepat digunakan di era milenial ini dengan berbasis al-Qur'an.

Penelitian ini berbasis library-reseacrh yang mengumpulkan datadata dari berbagai literatur dan penelitian sebelumnya. Data yang telah terkumpul dianalisis kemudian disajikan secara deskriptif-analitik. Selanjutnya, melalui tulisan ini, penulis merumuskan solusi guna menghadapi permasalahan radikalisasi di Indonesia yang menyebar melalui teknologi informasi.

\section{Pembahasan}

\section{Perilaku Radikal Manusia}

Di Indonesia, Islam radikal dimulai dengan kemuculan Darul Islam di berbagai kota dan partai Masyumi (Majelis Syura Muslimin Indonesia) yang sering mengadakan kontak transnasional dengan beberapa gerakan di Timur Tengah (Umar). Kemudian, gerakan Islam radikal yang populer di seluruh dunia yaitu ISIS. Di negeri ini, ISIS mendapat dukungan dari Mujahidin Indonesia Timur, Jamaah Ansharut Tauhid, Jama'ah Islamiyah, Forum Aktivis Syariat Islam, Awhid wal Jihad dan lain-lain (Terorisme, Badan Nasional Penanggulangan). Kelompok lain seperti Front Pembela Islam (FPI), Hisbut Tahrir, Laskar Mujahidin, Laskar Hizbullah, Laskar Jundullah dan seterusnya juga dianggap sebagai gerakan-gerakan radikalfundamentalis yang muncul pasca Orde Baru (Rouf).

Dalam merespon masalah ini, BNPT melakukan tiga tindakan yaitu pencegahan dengan menanamkan nilai-nilai ke-Indonesiaan dan anti- 
kekerasan serta deradikalisasi (praktik mendorong penganut ideologi agama atau politik yang radikal untuk mengadopsi pandangan yang lebih moderat) untuk mematahkan gerakan kelompok militan yang menggunakan cara kekerasan dan teror serta memoderasi paham-paham radikal mereka (Terorisme, Badan Nasional Penanggulangan).

Sejarah membuktikan aksi terorisme mulai dari skala kecil hingga berskala besar telah menimbulakn kerusakan dan memakan banyak korban jiwa. Salah satu peristiwa terorisme terbesar yang tidak akan dilupakan sejarah adalah serangan pada 11 September 2001 terhadap gedung World Trade Center, New York Amerika Serikat yang menewaskan kurang lebih 3000 orang dan melukai 6000 orang. Kemudian, Pengeboman kereta commuter Cercanias di kota Madrid, Spanyol pada 11 Maret 2004. Peristiwa ini membunuh orang sabanyak 192, melukai sekitar 2000 orang dan mejadi peristiwa terorisme terbesar di Spanyol (Hardoko). Tak hanya di luar negeri, baru-baru ini Indonesia juga digegerkan dengan pengeboman tiga gerja di Surabaya yakni gereja Santa Maria Tak Bercela, GKI Diponegoro dan Gereja Pentakosta di Jalan Arjuna pada Minggu, 13 Mei 2018 (Hartadi). Tiga peristiwa tersebut hanyalah contoh dari sekian banyak peristiwa teroriseme di seluruh dunia yang diakibatkan perilaku radikal manusia.

Dari peristiwa-peristiwa terorisme yang muncul dari penyebaran paham radikalisme tersebut dapat dikategorikan sebagai peristiwa pertumpahan darah di muka bumi. Dalam al-Qur'an, peristiwa pertumpahan darah diantara manusia disebutkan dalam Surat al-Baqarah ayat 30 yang artinya:

Ingatlah ketika Tuhanmu berfirman kepada para malaikat: "Sesungguhnya Aku hendak menjadikan seorang khalifah di muka bumi." mereka berkata: "Mengapa Engkau hendak menjadikan (khalifah) di bumi itu orang yang akan membuat kerusakan padanya dan menumpahkan darah, padahal kami senantiasa bertasbih dengan memuji Engkau dan mensucikan Engkau?" Tuhan berfirman: "Sesungguhnya Aku mengetahui apa yang tidak kamu ketahui."

Dalam Tafsir Jalalain, perilaku manusia yang akan berbuat kerusakan dan menumpahkan darah sudah diketahui oleh malaikat sebelum Nabi Adam diciptakan. Menumpahkan darah dijabarkan dengan mengalirkan darah dengan jalan pembunuhan sebagaimana dilakukan oleh bangsa jin yang juga mendiami bumi (As-Suyuthi). Sedangkan menurut Quraish Shihab dalam Tafsir Al-Misbah, perilaku manusia yang merusak dan menumpahkan darah baru sebatas pada dugaan malaikat saja. Dugaan tersebut bisa jadi berasal dari pengalaman mereka sebelum terciptanya 
manusia, dimana terdapat makhluk yang berlaku demikian. Kemungkinan lain, dugaan ini juga berangkat dari asumsi bahwa manusia ini berbeda dengan para malaikat yang selalu menyembah dan bertasbih kapada Allah. Kemudian pernyataan malaikat ini juga dapat muncul dari penamaan Allah terhadap makhluk yang akan diciptakan yaitu khalifah yang mengesankan makna pelerai peselisihan dan penegak hukum, sehingga dapat dipastikan di antara mereka akan ada perselisihan dan pertumpahan darah. Quraish Shihab menambahkan bahwa yang menumpahkan darah bisa jadi bukan Adam namun anak cucunya (Shihab).

Lain halnya dengan Wahbah Zuhaili yang menambahkan penafsiran bahwa perbuatan manusia itu dikarenakan manusia berbuat berdasarkan pilihan dan kemauan sendiri. Di samping itu manusia juga tercipta dari tanah. Materi merupakan bagian dari mereka sehingga ia lebih dekat dengan kesalahan. Sedangkan, malaikat mengetahui bahwa merekalah makhluk yang terjaga dari kesalahan. Maka makhluk selain malaikat tentu memiliki sifat yang berbeda dengan mereka. Dalam tafsir ini perilaku menumpahkan darah dikarenakan adanya sikap permusuhan dan keangkuhan (Az-Zuhaili).

Dari pertanyaan malaikat "Mengapa Engkau hendak menjadikan (khalifah) di bumi orang yang akan membuat kerusakan padanya dan menumpahkan darah, padahal kami senantiasa bertasbih dengan memuji Engkau dan menyucikan Engkau?", Allah menjawab dengan singkat "Sesungguhnya Aku mengetahui apa yang tidak kamu ketahui". Jawaban ini tidak membenarkan maupun menyalahkan pernyataan dalam pertanyaan malaikat karena memang akan ada di antara yang diciptakan Allah SWT tersebut melakukan perbuatan seperti yang ada dalam dugaan malaikat (Shihab).

Sejarah membuktikan bahwa dugaan malaikat menjadi kenyataan. Surat al-Maidah ayat 31 merekam peristiwa pertumpahan pertama yang dilakukan oleh anak Adam, Qabil dan Habil. Di samping itu berbagai macam peperangan dan tindak kedzaliman manusia yang memakan korban jiwa menjadi fakta tak terelakkan yang terjadi hampir di setiap fase kehidupan umat manusia sejak masa kenabian hingga hari ini. Maka, peristiwa pertumpahan darah yang dapat kita lihat saat ini contonya adalah berbagai perilaku radikal suatu kelompok kepada kelompok lain yang mengorbankan nyawa manusia. 


\section{Manusia Sebagai Khalifah}

Manusia diciptakan dengan mengemban tugas sebagai khalifah, melaksanakan ibadah (menyembah Allah), 'imarah (menghuni dan memakmurkan bumi) dan imamah (orang yang diikuti jejaknya dan didahulukan urusannya). Khalifah akar katanya khalafa-yakhlufukhalfan-khalafan-khilafatan yang berarti berada di belakang, pihak yang datang di belakangnya dan berada pada posisinya, pengganti, yang datang sesudahnya, yang ditempatkan sebagai pengganti bagi yang sebelumnya (Lajnah Pentashih Mushaf Al-Qur'an).

Menjadi khalifah fil-ardh merupakan keistimewaan manusia diantara makhluk lain. Dalam surat al-Azhab ayat 72 Allah berfirman:

Artinya: "Sesungguhnya kami Telah mengemukakan amanat kepada langit, bumi dan gunung-gunung, Maka semuanya enggan untuk memikul amanat itu dan mereka khawatir akan mengkhianatinya, dan dipikullah amanat itu oleh manusia. Sesungguhnya manusia itu amat zalim dan amat bodoh"

Ayat ini menunjukkan hanya manusia saja yang menerima dan mampu mengemban amanat sebagai khalifah, sedangkan makhluk lain tidak mampu dan tidak bersedia. Segala apa yang di ciptakan di bumi diperuntukkan bagi kepentingan manusia. Selain itu manusia juga dibekali hidayatul-ilham (insting), hidayatul-hawwas (indra), hidayatul-'aql (intelegensi) dan hidayatul-adyan wasy-syariat (hukum-hukum agama) (Lajnah Pentashih Mushaf Al-Qur'an).

Dalam surat Sad ayat 26 dijelaskan bahwa Nabi Daud sebagai khalifah harus melaksanakan hukum diantara manusia berdasarkan kebenaran dan keadilan serta tidak menuruti hawa nafsu (Lajnah Pentashih Mushaf Al-Qur'an). Sedangkan dalam surat an-Naml ayat 62, manusia dijadikan khalifah di bumi untuk mampu memanfaatkan kekayaan alam dan hidup nyaman di permukaannya.

\section{Mengatasi Radikalisasi Melalui Teknologi Informasi}

Dari uraian di atas jelas bahwa Islam menolak perilaku radikalisme. Karena itu perilaku semacam ini harus di hapuskan secara total. Menangani radikalisme ini menjadi bagian dari tugas manusia sebagai khalifah yang harus menegakkan kebenaran dan keadilan. Deradikalisasi ini perlu dilakukan dengan tindakan berlapis yaitu pencegahan, sikap dalam menghadapi radikalisme yang sedang terjadi dan cara menghilangkannya di tengah masyarakat.

\section{Wawasan Al-Qur'an Tentang Radikalisme}


Saat ini umat manusia hidup di era digital dimana teknologi informasi memberi pengaruh begitu besar di setiap lini kehidupan. Berbagai kemudahan dan peluang muncul seiring berkembangnya kecanggihan teknologi. Namun, disisi lain kejahatan dan berbagai hal bathil juga semakin mendapat tempat untuk berkembang dan menyebar luas. Seperti itu pula penyebaran radikalisme yang semakin merajalela terutama melalui berbagai media sosial. Berdasarkan penelitian yang dilakukan oleh Pusat Studi Budaya dan Perubahan Sosial (PSBPS) Universitas Muhammadiyah Surakarta (UMS) sejak September-November 2017 disimpulkan bahwa Facebook masih menjadi media yang potensial untuk menyebarkan radikalisme (Taher). Twitter, Instagram, Telegram, Youtube hingga Game Online juga menjadi sarana penyebaran radikalisme.

Atas alasan diatas penulis hendak memberikan solusi Qur'ani menangani perkembangan paham radikalisme yang menyebar melalui teknologi informasi terutama karena derasnya arus informasi melalui media sosial. Solusi tersebut antara lain:

a) Amar Ma'ruf Nahi Munkar

Dalam al-Qur'an Surat Ali-Imran ayat 104 disebutkan:

Artinya: "Dan hendaklah ada di antara kamu segolongan umat yang menyeru kepada kebajikan, menyuruh kepada yang ma'ruf dan mencegah dari yang munkar merekalah orang-orang yang beruntung."

Amar ma'ruf nahi munkar tentu menjadi salah satu tugas seorang khalifah. Mengajak pada kebaikan dalam konteks ini dapat dilakukan dengan membekali masyarakat dengan pemahaman agama yang dalam (terutama karena radikalisme seringkali membawa isu agama) dan kecakapan serta kecermatan dalam menggunakan teknologi informasi. Sedangkan mencegah pada yang munkar dapat dilakukan dengan diberlakukannya larangan penyalahgunaan media serta melakukan upaya filtrasi terhadap media yang mengandung konten negatif seperti paham radikalisme

b) Tabayyun

Produsen informasi tidak boleh membuat informasi yang memuat konten ajakan atau memberi paham radikal. Begitu pula ketika hendak menyebarkan informasi, seseorang perlu melakukan klarifikasi (tabayun) terlebih dahulu sebelum menyebarkan informasi kepada orang lain. Kemudian sebagai konsumenn berita, masyarakat harus kritis dan tidak begitu saja terpengaruh dengan informasi yang di dapatkan. Hal ini selaras dengan surat Hujurat ayat 6, Artinya: Hai orang-orang yang 
beriman, jika datang kepadamu orang fasik membawa suatu berita, Maka periksalah dengan teliti agar kamu tidak menimpakan suatu musibah kepada suatu kaum tanpa mengetahui keadaannya yang menyebabkan kamu menyesal atas perbuatanmu itu.

c) Uqubah

Untuk menghilangkan perilaku radikalisme manusia, maka perlu ditetapkan hukuman bagi orang yang menyebarkan radikalisme. Uqubah adalah hukuman yang telah atau dapat ditetapkan atas pelanggaran terhadap perintah dan larangan syar'i (Allah dan RasulNya) untuk menjamin kemaslahatan masyarakat. Tujuannya adalah untuk memperbaiki perikau manusia, memelihara mereka dari segala bentuk kerusakan (masfsadat), menghindarkan mereka dari kesesatan, mengajak mereka untuk menaati Allah dan Rasul-Nya, dan meredam seluruh bentuk perbuatan maksiat (Lajnah Pentashih Mushaf AlQur'an). Dalam surat Al-Maidah ayat 33-34 disebutkan:

Artinya: Sesungguhnya pembalasan terhadap orang-orang yang memerangi Allah dan rasul-Nya dan membuat kerusakan di muka bumi, hanyalah mereka dibunuh atau disalib, atau dipotong tangan dan kaki mereka dengan bertimbal balik, atau dibuang dari negeri (tempat kediamannya). yang demikian itu (sebagai) suatu penghinaan untuk mereka di dunia, dan di akhirat mereka beroleh siksaan yang besar. Kecuali orang-orang yang Taubat (di antara mereka) sebelum kamu dapat menguasai (menangkap) mereka; Maka Ketahuilah bahwasanya Allah Maha Pengampun lagi Maha Penyayang.

\section{Simpulan}

Perilaku radikal yang terjadi di antara manusia telah di prediksi oleh malaikat sebelum manusia pertama (Adam) diciptakan. Perilaku radikal ini menyebabkan pertumpahan darah melalui peperangan, pembunuhan dan lain-lain. Dalam sejarah umat manusia, peristiwa pertumpahan darah pertama terjadi diantara Habil dan Qabil. Selanjutnya peristiwa peperangan dan pembunuhan juga terjadi di sepanjang babak kehidupan umat manusia. Kemudian, pada masa sekarang ini pertumpahan darah terjadi salah satunya disebabkan aksi terorisme yang dilakukan kelompok radikal. Manusia yang diamanahi sebagai khalifah di bumi memiliki tugas untuk menghentikan meluasnya paham radikal yang melahirkan perilaku radikal atau terorisme. Oleh karena teknologi informasi menjadi ladang yang sangat subur penyebaran radikalisme ini, maka upaya deradikalisasi melalui media sosial juga sangat penting dilakukan. Upaya menanggulangi 
radikalisasi dapat dilakukan dengan mengajak pada kebaikan dan mencegah pada keburukan, menanaman sikap tabayyun dan menghukum pelaku penyebar paham radikal agar mereka jera dan masyaraat menjauhkan diri dari perilaku tersebut. Dengan beberapa solusi tersebut diharapkan dapat terwujud Islam yang moderat, anti terhadap kekerasan, ekstrimisme dan paham yang menyimpang.

\section{DAFTAR PUSTAKA}

Al-Mahali, Imam Jalaluddin dan Imam Jalaluddin Sa-Suyuthi. Tafsir Qur'anil 'Adziim. Penerbit Pustaka An-Nisa tt

Aplikasi KBBI V Offline, Badan Pengembangan Dan Pembinaan Bahasa, Kemetrian Pendidikan Kebudayaan Republik Indonesia, 2016 diakses pada Selasa, 3 November 2018 pukul 23.10 WIB

Az-Zuhaili, Wahbah. 2012. Tafsir Al-Wasith: Al-Fatihah-At-Taubah (Depok: Gema Insani)

Badan Nasional Penanggulangan Terorisme, Strategi menghadapi Paham Radikalisme Terorisme- ISIS, http://belmawa.ristekdikti. go.id/wp-content/uploads / 2016/12/Strategi-Menghadapi-PahamRadikalisme-Terorisme.pdf\&ved $=$ 2ahUKEwjNrvC927veAhUHPY8KH TJRBVgQHFjAAegQIAxAB\&usg= AovVaw1j25DcIZdJHrDz86eJoIDH diakses pada 5 November 2018 pukul 05.03 WIB

Hardoko, Ervan. 2016. 10 Aksi Teror Paling Banyak Memakan Korban Jiwa Sepanjang Abad 21, http://style.tribunnews.com/2016/09/11/10aksi-teror-paling-banyak-menelan-korban-jiwa-sepanjang-abad21?page $=4$ diakses pada 6 November 2018 pukul 12.41 WIB

Hartadi, Budi. 2018. Bom Meledak di 3 Gereja di Surabaya. https://m. detik.com/news / berita/d-4018010/bom-meledak-di-3-gereja-disurabaya diakses pada 7 November 2018 pukul 02.50 WIB

Juhri, Muhammad Alan Dakwah Anti Radikal Perspektif Al-Qur'an Dalam Merawat Kebhinekaan Indonesia (Telaah Kandungan Ayat-ayat Dkawah Qs. An-Nahl: 125 dan Qs. Al-Baqarah : 256) dalam Senarai Penelitian Islam Kontemporer: Tinjauan Multikultural (Yogyakarta: Deepublish Publisher: 2018) 
Lajnah Pentashih Mushaf Al-Qur'an. 2017. Tafsir Al-Qur'an Tematik. Jilid 8 Cetakan Keempat (Jakarta: Kamil Pustaka)

Lajnah Pentashih Mushaf Al-Qur'an. 2017. Tafsir Al-Qur'an Tematik. Jilid 9 Cetakan Keempat (Jakarta: Kamil Pustaka)

Lajnah Pentashih Mushaf Al-Qur'an. 2017. Tafsir Al-Qur'an Tematik. Jilid 1 Cetakan Keempat (Jakarta: Kamil Pustaka)

Mundir. 2016. Menakar Kebebasan Media Massa Dan Radikalisme Agama. Jurnal Edcomtech Volume 1 No. 2 Oktober 2016

Ro'uf, Abdul Mukti. Mengurai Radikalisme Agama Di Indonesia Pasca Orde Baru dalam Jurnal Ulumuna Volume XI No. 1 Juni 2007

Shihab, M. Quraish. 2000. Tafsir Al-Misbah: Pesan, Kesan dan Keserasian Al-Qur'an. Jilid 1 Cetakan Pertama (Ciputat: Penerbit Lentera Hati)

Taher, Andrian Pratama. 2017. Facebook Masih Jadi Lahan Penyebar Paham Radikalisme di Indonesia, https://tirto.id/facebook-masihjadi-lahan-penyebar-paham-radikalisme-di-indonesia-cA9w diakses pada 7 November 2018 pukul 14.42 WIB

Umar, Ahmad Rizky Mardhatillah. Melacak Akar Radikalisme Islam di Indonesiam. Jurnal Ilmu Sosial dan Ilmu Politik Volume XIV No. 2 